\title{
Investigation on Reform of Engineering Mathematics Teaching in the Mode of Skilled Talent Training
}

\author{
Dong-hong Zhao, Li Liu, Zhi-yi Zhao \\ University of Science and Technology Beijing, Beijing 100083, China
}

\begin{abstract}
The "outstanding engineers training plan" has been launched officially by the Ministry of Education of PRC on 10, Jun, 2010. University of Science and Technology Beijing (USTB) was been selected as the first listed colleges and universities in the plan among 61 fellows. The Department of Advanced Engineers was founded to satisfy the demand of this plan. It is of great significance to the training of advanced skilled engineers and the development of professions in USTB. With the background of outstanding engineers training plan, Department of Advanced Engineers puts forward the concept of basic courses of engineering. At the same time, there is innovative value in basic curriculum understanding, basic course structure, teaching method and requirement for teachers' curriculum innovation.
\end{abstract}

Index Terms - Excellent Engineers Education Program, Engineering and Technical Personnel, Engineering Mathematics, the Iron and Steel Enterprises, the Continuous Line of Mathematics

According to the 'excellent engineer education and training plan', the idea of Engineering Education under the background of the iron and steel industry with innovation is meant to solve the knowledge, application, theory, practice and the relationship of professional ability and comprehensive quality. Engineering basic course excellence program under the philosophy of education is an important innovation of basic courses. Based on basic curriculum structure, curriculum value basis teaching method and basic course teachers should have innovation performance requirements. According to the requirements of innovation, counter measures in applied undergraduate mathematics courses are: adjustment of engineering school mathematics teaching goal, basic curriculum structure, teaching method reform.

Mathematics is the basis of all engineering research field, especially some engineering technology in graduate school. Most of them have certain requirements in Mathematics. The integration of Mathematics and Engineering has become an urgent task on education development in the recent years.

It is important to combine the traditional mathematical content and engineering technology and optimize them to cultivate the students' ability of applied mathematics.

Because of the engineering background, it is convenient to focus on 'background', 'thinking', 'method', 'analyses' in the teaching of Engineering Mathematics. Students can quickly transform the knowledge into ability. Mathematics is no longer abstract and difficult. With the background of Engineering,

Grant by Teaching Reform Project of USTB

No.KC2013YJX17; JG2011Z13; JYBZYSD201207; JG2011ZB02

Grant by Research on the Training Mode of Innovative Talents, Beijing, 2012 students' ability and quality of Mathematics have been improved greatly.

With the development of Applied Mathematics, the integration of Mathematics and other disciplines has become a hot topic in China as the education develops.

Despite the importance of the application of Mathematics education has been recognized around the world and school has invested relatively more, Mathematics is still 'outside the core of teaching'.

School doesn't enjoy benefits brought by Mathematics more or less. However, through theoretical investigation and practice, applying Mathematics to remove the drawbacks and optimize traditional teaching content has become an important measure in promoting the teaching quality and cultivating innovative talent in the new century.

According to the characteristics of our school's training scheme, Department of Advanced Engineers has designed 6 years co-ordinating training program in 2009, 2010, 2011. The teaching plan has greatly strengthened the ability to study basic courses, emphasizing 'continuous line in practice, foreign language, thinking, mathematics'. In this context, the course of 'Engineering Mathematics' births. It combines with the engineering technology most closely in comparison with other subjects. And the application of engineering of this course is more extensive. The program aims to fade out the conclusion of theories and strengthen the ability of practice, making theory and application more close.

Firstly, aiming at the requirement of basic knowledge and ability of Mathematics, in accordance with 'bachelor-master' mode, doing reform of teaching systems, contents and methods

Secondly, in the background of 'excellence plan', proposing a Mathematics content that fits the engineering environment of USTB

Thirdly, in order to write and edit a teaching material on Engineering Mathematics fitting the engineering specialization

Fourth, doing the research, practice, summary twice

At last, we have written and edited a teaching material on Engineering Mathematics fitting every specialization in the Department of Advanced Engineers. Meanwhile, we also make multimedia coursewares in the class to realise the reform of teaching on Mathematics. We made sufficient investigations and research according to the outline of curriculum of Engineering Mathematics nationally and combine it the 
characteristics of needs of USTB to satisfy the concision and understandability. Our subject covers the Matrix, Optimization, Mathematical Statistics and Integral Transform. In accordance with characteristics of our school, we highlight profession and practicality to apply Mathematics to production practice as far as possible.

Mathematics as a system, the scientific system of rich content to help students cultivate good study style, set up correct world view can play an important role. In institutions of higher learning, the courses in mathematics teaching, long duration, which is very important for the growth of college students in the school during which have the effect. As the mathematical sciences in various fields more and more extensive and in-depth application of mathematics education for the important role of talent quality has become the consensus of people, thus a college students' mathematical quality is an important part of their comprehensive quality.

Many famous mathematician, industrious, moral legend life can become the model of contemporary college students; The creation and development of mathematical history can make people enlightenment and inspiration, therefore, mathematics course in institutions of higher learning education and moral education of the organic combination is an important segment of the talent comprehensive quality education. Followed by pay more attention to the effect of teaching mode in students' mathematical ability, historically, have to undergo a descriptive any subject, three stage of the experimental and theoretical mathematics course education is no exception. Generally speaking, according to the cognitive principle, mathematics education should guide students from intuitive specific experimental enter the stage of abstract theory.

Therefore, the implementation of diversified teaching mode, the pure teacher-centered, with the center of the classroom teaching mode innovation to take the student as the center, combined with mathematical experiment and other diversified teaching mode. For centuries in the future, in terms of social environment, and with the further development of science and technology, further improve the production efficiency, competition will become more and more fierce, in order to adapt to the environment, people should be a generalist, and constantly updated knowledge. Ability to obtain knowledge, therefore, will be the future talent should have the ability of the most important, this in institutions of higher learning, to occupy the course, long-lasting mathematics teaching the role of it is self-evident, from another point of view, mathematics educators need to study this subject

With the rapid development of science and technology, dramatically expand the application scope of mathematics. Can say that the application of mathematics is to permeate into all areas . Computer powerful computing and graphics functions, forcing people to math concepts must be updated, mathematics teaching requires a profound revolution, the revolution should not only on the teaching content, and it also included on the teaching methods and teaching means, need to carry out on each course in mathematics, as applied probability theory and mathematical statistics course teachers need more seriously study the new situation and new task faced by the current.

\section{References}

[1] Dong Hong Zhao, Na Li, Xiang Kui Zhao, Fu Cheng Liao. Mathematical simulation experiment in the teaching of probability theory and mathematical statistics,Higher science education, 2010(2): 175 - 177.

[2] R.Bellman. Introduction to Matrix Analysis. New York: McGrawHill, 1970.

[3] Tongji university applied mathematics. Engineering mathematics. Shang Hai: Tongji university press, 2002。

[4] L.A.Hagman, D.M.Young. Applied Interactive Methods. New York/London: Academic Press, 1981.

[5] Pei Hong Cheng, Jin Xia Wang. The "outstanding engineers training oriented theoretical physics curriculum reform. Journal of ningbo college of engineering, vol.24, No 2,23-27. 